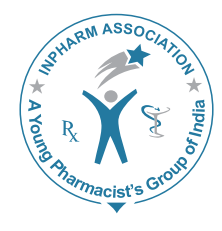

\title{
Preparation and Evaluation of Mixture of Eudragit and Ethylcellulose Microparticles Loaded with Ranolazine for Controlled Release
}

\author{
Gowda DV, Gowrav MP, Gangadharappa HV, Khan MS \\ Department of Pharmaceutics, JSS College of Pharmacy, JSS University, Mysore, Karnataka, India \\ Address for correspondence: Dr. D. V. Gowda; E-mail:dvgowda4@gmail.com
}

\begin{abstract}
To minimize the unwanted toxic effects of anti-anginal ranolazine by kinetic control of drug release, it was entrapped into gastro-resistant, biodegradable eudragit (EU) and ethyl cellulose $(E C)$ binary blend using phase separation method. Ten formulations were prepared using different polymer blend ratios and solvent. The prepared microparticles were characterized for micromeritic properties, polymer drug compatibility by Fourier Transform Infrared Spectroscopy (FT-IR) and Differential Scannibg Calorimetry (DSC), and surface morphology by Scanning Electron Micrography (SEM). The yield of microparticles was up to $90 \%$ and more than $98 \%$ of the isolated microparticles are having volume mean diameter of $285 \mu \mathrm{m}$. The obtained angle of repose, percentage Carr's index and tapped density values were within the limits indicating good flow properties. The surface morphology revealed that particles were free-flowing, spherical, with minute pores and invert dents on the surface. The prepared microparticles were evaluated for percentage yield, encapsulation efficiency and in vitro release studies. FT-IR and DSC studies showed no chemical interaction between the drug and used polymers The in vitro drug release studies were carried out using pH 1.2 acid buffer and pH 7.4 phosphate buffer. EU acts as an excellent $\mathrm{pH}$-dependent binder and helps to release the drug in the intestine. The drug release kinetics followed different transport mechanisms. Increasing the weight fractions of EU and decreased EC helps to control the drug release from the particles. From the differential $\left(f_{1}\right)$ and similarity factor $\left(f_{2}\right)$, Formulation F5 was the formulation most similar to the commercially available oral formulation as reference standard. The drug release performance was greatly affected by the materials used in microparticle preparations, which allow absorption in the intestinal tract.
\end{abstract}

Key words: Ethyl cellulose, eudragit, kinetic drug release, microparticles, ranolazine

\section{INTRODUCTION}

In recent years, considerable attention has been focused on

\begin{tabular}{|l|l|}
\hline \multicolumn{2}{|c|}{ Access this article online } \\
\hline Quick Response Code: & \\
\hline & Website: \\
\hline & www.jyoungpharm.in \\
& DOI: \\
\hline
\end{tabular}

the development of novel drug delivery system (NDDS). The reason for this paradigm shift is the low development cost and time required for introducing an NDDS, as compared to a new chemical entity. In the form of NDDS, an existing drug molecule can get a new life, thereby increasing its market value, competitiveness, and product and product patent life. Among the various NDDS available in the market, the oral controlled release systems hold a major portion of the market because of their ease of administration and better patient compliance. ${ }^{[1]}$ In the conventional oral drug delivery, which is a convenient method to achieve both local 
and systemic effects, there is a little or no control over drug release from dosage forms. An effective concentration at the target site can be achieved by intermittent administration of a grossly excessive dose, which results in constantly changing, unpredictable, and often sub or supra therapeutic plasma concentration, leading to marked side-effects. ${ }^{[2]}$

The goal of any drug delivery is to provide a therapeutic amount of drug to the proper site in the body in order to promptly achieve and thereby to maintain the desired drug concentration during treatment. The idealized objective can be achieved by a controlled release mechanism of a poorly water-soluble drug, which easily mixes with the mixture of polymeric matrix and shows good absorption rate. The mixture of the polymeric matrix materials used in the present study has good pharmaceutical properties. However, the reported methods are not suitable for all drugs. Among the reported conventional methods different strategies have been developed. In recent years many research have already been carried out in order to design different types of matrix-type microparticles loaded with hydrophilic and lipophilic drugs using toxic solvents. The use of such solvents during formulation is of environmental concern and challenges human safety. To overcome this problem, in the present study, water has been used to prepare matrix-type microparticles by phase separation method. Moreover, these matrix-type microparticles offer double benefits. Firstly, particle size is reduced to a minimum level and secondly, the presence of insoluble polymer(s) in the matrix would modify the drug release rate by changing the matrix permeability.

Ranolazine (RNZ), a novel anti-anginal agent belonging to the group of piperizine acetamide has been widely used in the treatment of cardiovascular diseases, including arrhythmias, variant and exercise-induced angina, and myocardial infarction. ${ }^{[3]}$

It has been reported that RNZ improves the myocardial oxygen balance between the supply and demand of the ischemic heart, by increase in the coronary blood flow. However, to achieve and maintain the drug concentrations within the therapeutic range, it is often obligatory to take the dosage forms several times a day. The most frequently reported side-effects (unwanted effects) occurring in more than $2 \%$ of people taking RNZ include the following: Dizziness, headache, constipation, nausea.

Oral controlled multiparticulate dosage forms such as microparticles are becoming more popular than the single-unit dosage form. Microparticles showed more reproducible drug absorption and reduced risk of local irritation at the gastrointestinal tract.
Eudragit (EU) and ethyl cellulose (EC) have been used as drug carriers to achieve controlled drug delivery for the past few decades. These polymers have gained a lot of interest owing to their versatile properties.

The present study aims to prepare RNZ microparticles using the phase separation method and to characterize the microparticles for micromeritic properties, drug loading, Fourier Transform-Infrared Spectroscopy (FT-IR), differential scanning calorimetry (DSC) and in vitro release studies.

\section{MATERIALS AND METHODS}

RNZ was provided as a gift sample by Zydus Cadila Healthcare Ltd., Ahmedabad. EU RLPO was provided as a gift sample from Degussa India Pvt. Ltd., Mumbai. ECL was purchased from Loba Chemie Pvt. Ltd., Mumbai. All other reagents used were of analytical grade.

Preparation of microparticles

Drug-loaded microparticles were prepared by phase separation method. ${ }^{[4]}$ Weighed amounts of RNZ were dissolved in $70 \mathrm{ml}$ of acetone and this solution was added to EU and ECL polymer blend at different ratios. Under constant stirring at $3000 \mathrm{rpm}, 30 \mathrm{ml}$ of non-solvent, purified water was added drop-wise to the drug and the polymer solution $(1 \mathrm{ml} / \mathrm{min})$. In the course of the water addition, the drug and the polymer were co-precipitated out to form microparticles. The resultant microparticles were separated by vacuum filtration and dried at room temperature for $72 \mathrm{~h}$. The dried microparticles were stored in a desiccator at room temperature. Formulation chart is presented in Tables 1 and 2.

\section{Characterization of microparticles}

Particle size analysis

The particle size was measured using a Malvern MASTERSIZER 2000 version 5.1 (Malvern, UK.) The samples of RNZ microparticles were dispersed in methanol in a ratio of 1:20 and measured at a temperature of $37^{\circ} \mathrm{C} \cdot{ }^{[5,6]}$

\section{Angle of repose}

Fixed-funnel method was employed for determining angle of repose. The angle of repose (q) for samples was calculated using the formula,

Angle of repose $(\theta)=\tan ^{-1}(\mathrm{~h} / \mathrm{r})$ 
Table 1: Formulation chart of prepared RNZ-loaded microparticles from F1 to F5

\begin{tabular}{lccccc}
\hline Ingredients & F1 & F2 & F3 & F4 & F5 \\
\hline RNZ (mg) & 300 & 300 & 300 & 300 & 300 \\
EU RLPO (mg) & 150 & 100 & 200 & 75 & 225 \\
EC (mg) & 150 & 200 & 100 & 225 & 75 \\
Acetone (ml) & 70 & 70 & 70 & 70 & 70 \\
Purified water (ml) & 30 & 30 & 30 & 30 & 30 \\
\hline
\end{tabular}

\section{Compressibility}

Tapped density was determined by placing a graduated cylinder containing a known mass of powder on a mechanical tapper apparatus (Electro lab tap density tester). Carr's index was calculated using the formula Carr's index $=($ tapped density - bulk density $) /$ tapped density

\section{Fourier transform infrared spectroscopy}

Drug polymer interactions were studied by Fourier TransformInfrared Spectroscopy (FT-IR) spectrophotometer (Shimadzu, 8033, USA) by KBr pellet method. ${ }^{[7]}$ The IR spectrum of the pellet from $400-4000 \mathrm{~cm}^{-1}$ was recorded.

\section{Differential scanning calorimetry}

All dynamic differential scanning calorimetry (DSC) studies were carried out on dupont thermal analyzer with 2010 DSC module. ${ }^{[8]}$ The instrument was calibrated using high-purity indium metal as standard. The dynamic scans were taken in nitrogen atmosphere at the heating rate of $10^{\circ} \mathrm{C} / \mathrm{min}$.

\section{Scanning electron microscopy}

Scanning electron microscopy (SEM) photographs were taken for the prepared microparticles with a scanning electron microscope, Joel-LV-5600, USA, at the required magnification in room temperature. The photographs were observed for morphological characteristics. Photographs were taken at the magnifications of $400 \times, 1500 \times$ and $3000 \times .^{[9,10]}$

\section{Percentage yield}

The yield was determined by weighing the microparticles and then finding out the percentage yield with respect to the weight of the input materials, i.e. weight of drug and polymer mixtures used. The formula for calculation of percentage yield is as follows;

$\%$ yield $=\frac{\text { wt. of drug polymer mixture }}{\text { wt. of microparticles }} \times 100$

Drug loading and encapsulation efficiency

One hundred mg of RNZ microparticles were weighed
Table 2: Formulation chart of prepared RNZ-loaded microparticles from F6 to F10

\begin{tabular}{lccccc}
\hline Ingredients & F6 & F7 & F8 & F9 & F10 \\
\hline RNZ (mg) & 300 & 300 & 300 & 300 & 300 \\
EU RLPO (mg) & 150 & 100 & 200 & 75 & 225 \\
EC (mg) & 150 & 200 & 100 & 225 & 75 \\
DMF (ml) & 30 & 30 & 30 & 30 & 30 \\
Acetone (ml) & 40 & 40 & 40 & 40 & 40 \\
Purified water (ml) & 30 & 30 & 30 & 30 & 30 \\
\hline
\end{tabular}

and transferred to a $100-\mathrm{ml}$ volumetric flask containing $\mathrm{pH} 7.4$ phosphate buffer. From this, $1 \mathrm{ml}$ of solution was transferred to a $10-\mathrm{ml}$ volumetric flask and diluted. Further $1 \mathrm{ml}$ of this solution was diluted to $10 \mathrm{ml}$ and absorbance was measured at $270 \mathrm{~nm} \cdot{ }^{[1]}$ The drug content was calculated by using the formula:

Amount of drug

$=\frac{\text { Conc. from standard graph } \times \text { dilution factor }}{1000}$

Percentage encapsulation efficiency was found out by calculating the amount of drug present in $100 \mathrm{mg}$ of microparticles.

In vitro drug release studies

The in vitro release of drug from the microparticles was carried out in basket-type dissolution tester USP XXIII, TDT-08L, with auto sampler containing $900 \mathrm{ml}$ of dissolution media ( $\mathrm{pH} 1.2$ buffer for the first $2 \mathrm{~h}$ and in $\mathrm{pH} 7.4$ phosphate buffer for the next $10 \mathrm{~h}$. The volume of the dissolution media was maintained at $900 \mathrm{ml}$ with constant stirring $(100 \mathrm{rpm})$ and temperature of bath was maintained at $37 \pm 0.5^{\circ} \mathrm{C}$. Aliquots $(10 \mathrm{ml})$ of dissolution media were sampled at specified time intervals and replaced with fresh media immediately after sampling. Samples were analyzed for drug content by Ultraviolet UV visible spectroscopy (Shimadzu UV 1601).The release data obtained were fitted into various mathematical models.

Dissolution studies were carried out for all the batches of the prepared formulations (10 batches) and compared with the commercial formulation Ranexa SR 200.

\section{Drug release kinetics}

In order to understand the mechanism and kinetics of drug release, the drug release data of the in vitro dissolution study was analyzed with various kinetic equations. Coefficient of correlation ( $r$ ) values were calculated for the linear curves obtained by the regression analysis of the above plots. ${ }^{[12]}$ A differential factor $\left(f_{1}\right)$ and similarity factor $\left(f_{2}\right)$ 
were calculated from the dissolution data according to the following equations:

$f_{1}=\frac{\sum_{t=1}^{n}\left|R_{t}-T_{t}\right|}{\sum_{t=1}^{n} R_{t}} \times 100$

$f_{2}=50 \log \left\{\left[1+\left(\frac{1}{n}\right) \sum_{t=1}^{n}\left(R_{t}-T_{t}\right)^{2}\right]^{-0.5} \times 100\right\}$

where, $\mathrm{f}_{1}-$ differential factor, $\mathrm{f}_{2}-$ similarity factor, $\mathrm{n}-$ number of time point, $\mathrm{R}_{\mathrm{t}}$ - dissolution value of the reference at time, ' $t$ ' and $T_{t}-$ dissolution value of test formulation at time ' $t$ '. Differential factor, $\mathrm{f}_{1}$ was calculated by the percentage difference between the two curves at each time point and measured the relative error between the two curves. The acceptable range for differential factor $f_{1}$ is $0-15$. The similarity factor $f_{2}$ was the logarithmic reciprocal square root transformation of the sum-squared error and is a measure of the similarity in the percentage dissolution between the reference and test products. The similarity value $\left(\mathrm{f}_{2}\right)$ obtained from dissolution profile of the reference and test products should be in the range 50-100.

\section{RESULTS AND DISCUSSION}

Ten formulations were prepared using different polymer blend ratios. The drug: Polymer ratio used in all the formulations was 1:1. Various formulation and process variables that could affect the preparation and properties of the microparticles were identified and optimized to get small, discrete, uniform, smooth-surfaced, and spherical microparticles. The formulation variables included concentration of the polymer blend and the solvent used. The process variables included the stirring speed and time.

In the first five formulations (F1-F5), the drug was dissolved in acetone and in the next five formulations (F6-F10), the drug was dispersed in dimethyl formamaide (DMF) and acetone.

An important factor that influences the size distribution of microparticles is the optimum stirring speed and time. A stirring speed of $3000 \mathrm{rpm}$ and $40 \mathrm{~min}$ stirring time was used to obtain reproducible microparticles. It was observed that with the increase in the stirring speed from $3000-3500 \mathrm{rpm}$, there was a decrease in the average size of the microparticles and recovery yield of the microparticles. It was due to the loss of microparticles that occurred during successive filtration. When the stirring speed was lower than $3000 \mathrm{rpm}$, larger microparticles were formed. The resultant microparticles were composed of irregular masses, which were not possible to distinguish as discrete individual microparticles are shown in the Figure 1.

When the stirring time was lower than $40 \mathrm{~min}$, it was observed that some amount of the dissolved mass adhered to the inner sides of the beaker, resulting in lower percentage yield. The effect of stirring time on percentage yield is presented in Table 3. As we increase the stirring time there will be more stirring time available which causes particle size to decrease to the extent that particle loss occurs during filtration process which reduces percent yield of microparticles.

From the above results it was observed that an optimum time of 40 min produces a good yield of microparticles. Formulation F5 showed better yield when compared to the other formulations, and results are presented in Table 4. Repeated batches of microparticles were prepared at an optimized rate (stirring speed and stirring time) which shows reproducibility of microparticles.

The flow property of the prepared RNZ microparticles was studied by determining the angle of repose $(\theta)$ and $\%$ compressibility index (CI). The obtained data along with

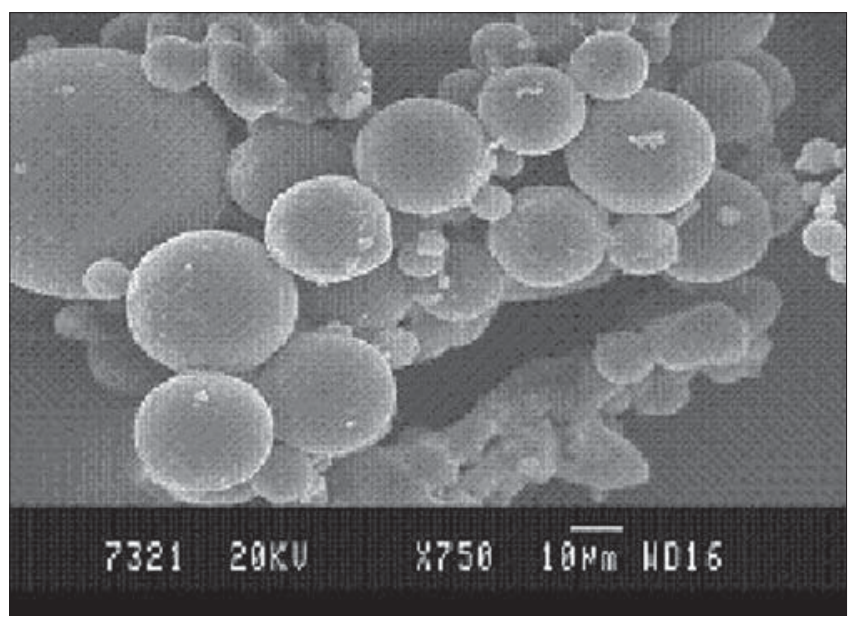

Figure 1: SEM photograph of RNZ microparticles obtained at low stirring speed

Table 3: Effect of stirring time on percentage yield of RNZ-loaded microparticles

\begin{tabular}{lc}
\hline Time in minutes & \% yield \\
\hline 10 & 45.11 \\
20 & 60.40 \\
30 & 79.22 \\
40 & 90.87 \\
50 & 88.08 \\
60 & 73.42 \\
70 & 62.72 \\
\hline
\end{tabular}


related parameters are presented in Table 5. The values of $\theta$ ranged from 26.24 to 29.12 and the Carr index was found to be between $11.22-15.01 \%$. These results indicated that the prepared microparticles exhibited good flow properties.

The values of tapped density ranged between $0.210-0.301 \mathrm{~g} / \mathrm{cm}^{3}$. The density difference between the formulations was negligible and the density values of formulations were well within the acceptable limits, indicating that the prepared microparticles were nonaggregated.

The average particle size/volume mean diameter (D [4, 3]) and volume median diameters ( $\mathrm{D}[\mathrm{v}, 0.5]),(\mathrm{D}[\mathrm{v}, 0.9])$ of the microparticle formulation of RNZ (F5) are given in Table 6 and the particle size graphs are given in Figure 2. $\mathrm{D}[4,3]$ is the volume mean diameter of the microspheres whose size is being determined. $\mathrm{D}[\mathrm{v}, 0.50]$ is the median diameter and it is the value of the particle size that divides the population into two equal halves i.e. there is $50 \%$ of distribution above this and $50 \%$ below this value. $\mathrm{D}[\mathrm{v}, 0.90]$ is the median diameter and it is the cutoff value for the distribution, which means $90 \%$ of the distribution (particle size value) is below this value.

Table 4: Percentage yield for RNZ-loaded microparticles

\begin{tabular}{lc}
\hline Formulation & \% Yield \pm SD $^{*}$ \\
\hline F1 & $86.22 \pm 1.44$ \\
F2 & $87.70 \pm 1.56$ \\
F3 & $86.46 \pm 1.24$ \\
F4 & $87.42 \pm 1.54$ \\
F5 & $91.44 \pm 1.36$ \\
F6 & $85.12 \pm 1.72$ \\
F7 & $86.32 \pm 1.12$ \\
F8 & $87.63 \pm 1.32$ \\
F9 & $84.43 \pm 1.26$ \\
F10 & $88.66 \pm 1.46$ \\
\hline
\end{tabular}

*Standard deviation, $n=3$

Table 5: Micromeritic properties of RNZ-loaded microparticles

\begin{tabular}{lccc}
\hline Formulation & $\begin{array}{c}\boldsymbol{\theta}^{\mathbf{0}} \\
\text { Mean } \pm \mathrm{SD}^{*}\end{array}$ & $\begin{array}{c}\mathbf{C I} \% \\
\text { mean } \pm \mathrm{SD}^{*}\end{array}$ & $\begin{array}{c}\text { Tapped density }\left(\mathrm{g} / \mathbf{c m}^{3}\right) \\
\text { mean } \pm \mathrm{SD}^{*}\end{array}$ \\
\hline F1 & $29.10 \pm 0.41$ & $14.25 \pm 0.66$ & $0.301 \pm 0.05$ \\
F2 & $28.75 \pm 0.11$ & $13.11 \pm 0.42$ & $0.245 \pm 0.02$ \\
F3 & $27.44 \pm 0.30$ & $14.22 \pm 0.28$ & $0.272 \pm 0.06$ \\
F4 & $28.45 \pm 0.33$ & $14.44 \pm 0.41$ & $0.225 \pm 0.06$ \\
F5 & $29.12 \pm 0.21$ & $13.45 \pm 0.67$ & $0.245 \pm 0.03$ \\
F6 & $28.11 \pm 0.36$ & $15.01 \pm 0.66$ & $0.224 \pm 0.01$ \\
F7 & $26.24 \pm 0.11$ & $11.22 \pm 0.65$ & $0.210 \pm 0.08$ \\
F8 & $29.12 \pm 0.51$ & $14.56 \pm 0.52$ & $0.299 \pm 0.01$ \\
F9 & $28.28 \pm 0.32$ & $13.42 \pm 0.22$ & $0.257 \pm 0.01$ \\
F10 & $28.23 \pm 0.26$ & $14.74 \pm 0.76$ & $0.260 \pm 0.02$ \\
\hline
\end{tabular}

*Standard deviation, $n=3$
RNZ pure drug and the optimized formulation were subjected for FT-IR spectroscopic analysis for compatibility studies and to ascertain whether there is any interaction between the drug and the polymers used [Figure 3]. From the data it is clear that similar characteristic peaks with minor differences were observed in drug and formulation. Hence it appears that there is no chemical interaction between the drug and the polymer. It can be concluded that the characteristics bands of pure drugs were not affected after successful loading. In order to investigate the possible interaction between the drug and the polymers, DSC studies were carried out. RNZ exhibits a sharp endothermic peak at 124.28 corresponding to its melting point and a similar condition was also observed in the formulation confirming the stability of the drug in the formulation [Figure 4].

SEM photographs showed that the drug-loaded microparticles were spherical in nature (mean size of around $285.9 \mu \mathrm{m}$ ), had a smooth surface with inward dents and shrinkage due to the collapse of the wall of the microparticles. SEM photographs shown in Figure 5 reveal the absence of drug particles on the surface of the

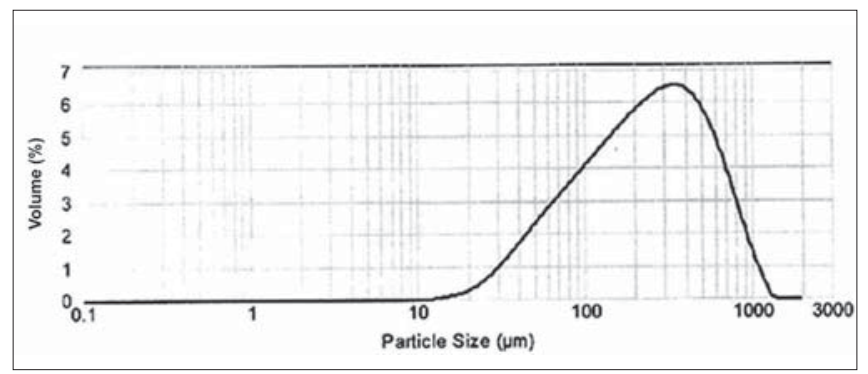

Figure 2: Particle size distribution of formulation F5

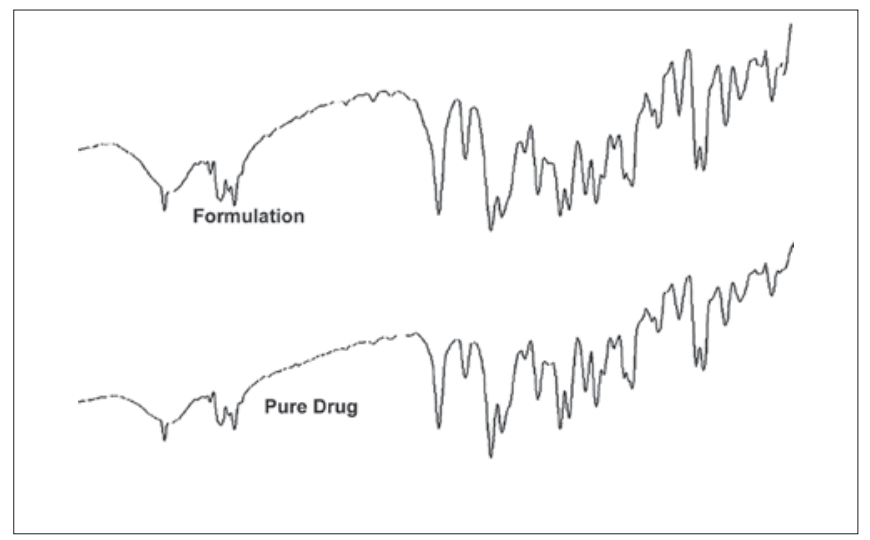

Figure 3: FT-IR spectra showing drug-polymer compatibility

Table 6: Particle size distribution parameters of RNZ microparticles

\begin{tabular}{lccc}
\hline Formulation & $\begin{array}{c}\text { Volume mean } \\
\text { diameter } \\
(\mathrm{D}[\mathbf{4}, 3]) \mu \mathrm{m}\end{array}$ & $\begin{array}{c}\text { Volume median } \\
\text { diameter } \\
(\mathrm{D}[\mathrm{v}, \mathbf{0 . 5 0}]) \mu \mathrm{m}\end{array}$ & $\begin{array}{c}\text { Volume median } \\
\text { diameter } \\
(\mathrm{D}[\mathrm{v}, \mathbf{0 . 9 0}]) \mu \mathrm{m}\end{array}$ \\
\hline F5 & 285.76 & 221.44 & 599.78 \\
\hline
\end{tabular}


microparticles indicating the uniform distribution of the drug in the walls of the microparticles.

The sphericity factor was obtained in the range 1.00 to 1.09 , indicating that the prepared formulations were spherical in nature.

Drug content was measured in order to ascertain that

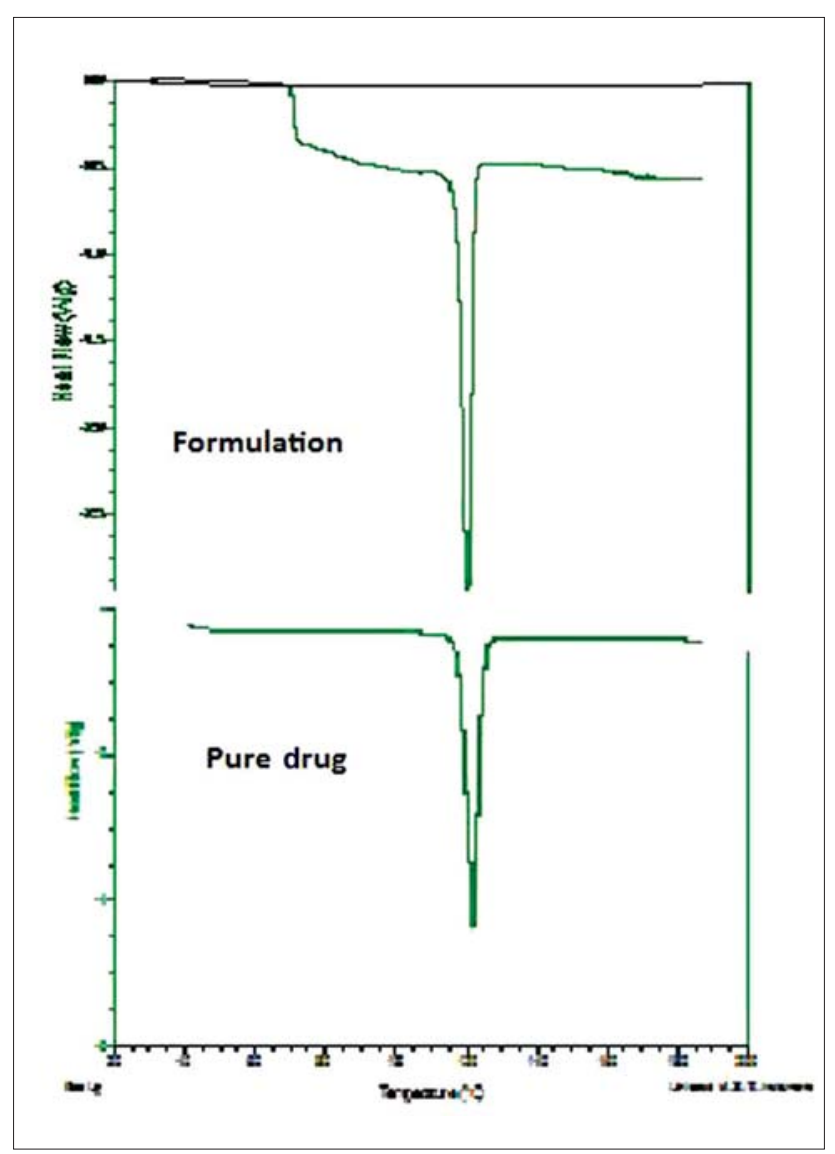

Figure 4: DSC comparison of pure drug and formulation F5

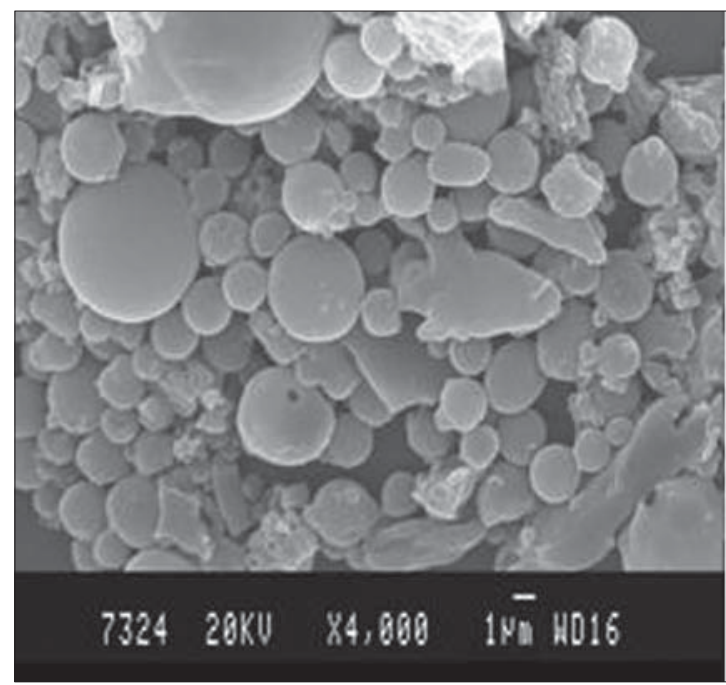

Figure 5: SEM photograph of formulation F5 the drug was uniformly distributed in the formulation. One hundred $\mathrm{mg}$ of the drug-loaded microparticles were taken in a $100 \mathrm{ml}$ volumetric flask containing $7.4 \mathrm{pH}$ buffer solution, and were shaken for $45 \mathrm{~min}$ and then filtered through Whatmann No.1 filter paper. The amount of RNZ present in the buffer solution was determined spectrophotometrically at $270 \mathrm{~nm}$. The percentage of drug loading in the formulations was found to be in the range of 36.35-45.23. The percentage encapsulation efficiency was found to be 65.25-89.66. The results obtained are given in Table 7. Formulation F5 showed maximum drug loading when compared to other formulations.

In vitro release studies were carried out for all formulations in both gastric and intestinal media. For the formulations F1-F10, as shown in Figure 6, it was noticed that the drug release rate decreases with increase in EC concentration. Studies also showed that the drug release rate increases with increase in EU RL 100 concentration. The drug release profile of optimized RNZ microparticle formulations was compared with the marketed formulation of RNZ (Ranexa SR) [Figure 7]. Among the prepared formulations the F5 formulation showed good controlled release effect based on release profile, similarity factor, differential factor, model fitting and release kinetics.

From the release studies it was observed that there is no significant release of drug in gastric $\mathrm{pH}$ from the microparticles and this indicates that the used polymer blend is gastro-resistant in nature. In intestinal $\mathrm{pH}$, drug was released in a biphasic manner consisting of an initial fast release stage followed by a slow release.

Initial drug release from drug-loaded microparticles in the intestinal environment was associated with initial burst

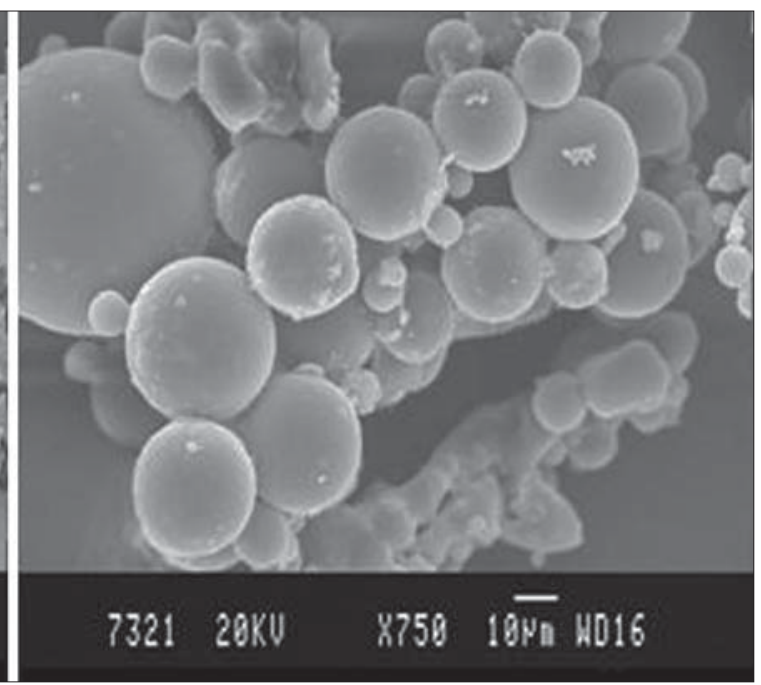




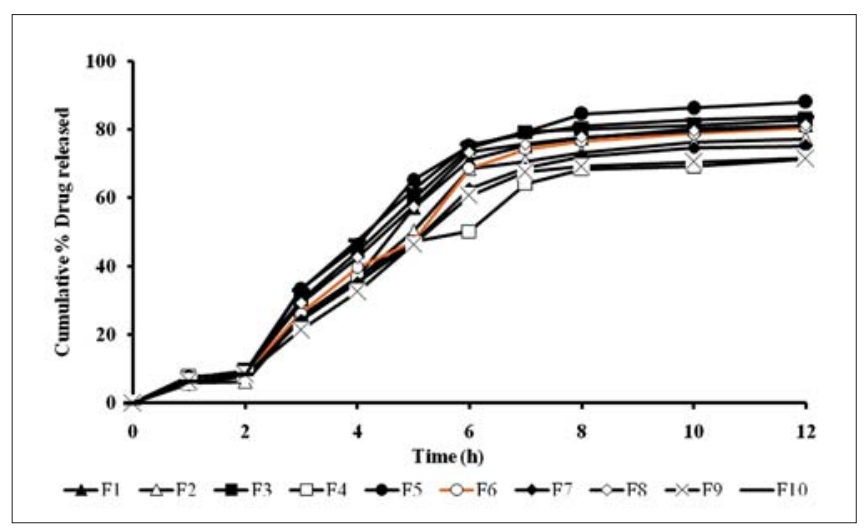

Figure 6: In vitro drug release profile of prepared RNZ microparticles'

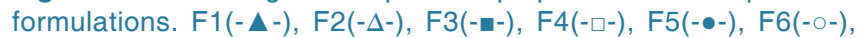
F7(-৬-), F8(-৩-), F9(-x-), F10(--)

Table 7: Drug loading and encapsulation efficiency of prepared microparticles

\begin{tabular}{lcc}
\hline Formulation & $\begin{array}{c}\text { Drug loading } \\
(\mathbf{m g}) \text { mean } \pm \mathrm{SD}^{*}\end{array}$ & $\begin{array}{c}\text { Encapsulation efficiency } \\
(\%) \text { mean } \pm \text { SD }^{*}\end{array}$ \\
\hline F1 & $41.21 \pm 0.36$ & $71.10 \pm 0.26$ \\
F2 & $39.42 \pm 0.57$ & $72.32 \pm 0.33$ \\
F3 & $41.32 \pm 0.56$ & $81.33 \pm 1.05$ \\
F4 & $37.50 \pm 0.44$ & $73.45 \pm 0.33$ \\
F5 & $45.23 \pm 0.36$ & $89.66 \pm 0.56$ \\
F6 & $40.21 \pm 0.26$ & $65.25 \pm 0.32$ \\
F7 & $36.35 \pm 0.33$ & $69.20 \pm 0.44$ \\
F8 & $39.72 \pm 0.42$ & $76.40 \pm 0.66$ \\
F9 & $36.70 \pm 0.38$ & $70.70 \pm 0.48$ \\
F10 & $41.60 \pm 0.44$ & $84.42 \pm 0.67$ \\
\hline
\end{tabular}

*Standard deviation, $n=3$

release. The burst release in the intestinal $\mathrm{pH}$ might be due to the release of surface-accumulated drug. After the initial burst effect, the subsequent release of the drug was slow and sustained. From the present study, it was observed EC (225:75) in a ratio of (225:75) i.e. a increase in EU concentration and a decrease in EC concentration helps to control the drug release from the particles.

The similarity factor fit the result between 50 and 100. It approached 0 as the dissimilarity of the test and the reference profile increased, whereas it attained 100 when the test and the reference profile were identical. The two profiles were believed to be similar when their $f_{1}$ value was between 0 to 15 (3.48 for F5) and their $f_{2}$ value was larger than 50 (82.1 for F5), for which the mean deviation over all time points ' $n$ ' was less than $10 \%$ based on above equation. Formulation 5 showed that it was most similar to the marketed reference standard.

Table 8 lists the composition of the RNZ microparticles, and expected and experimented values of all the formulations. From the presented results the release in $1 \mathrm{~h}$ varies in a non-linear fashion and with increase in the amount of EU

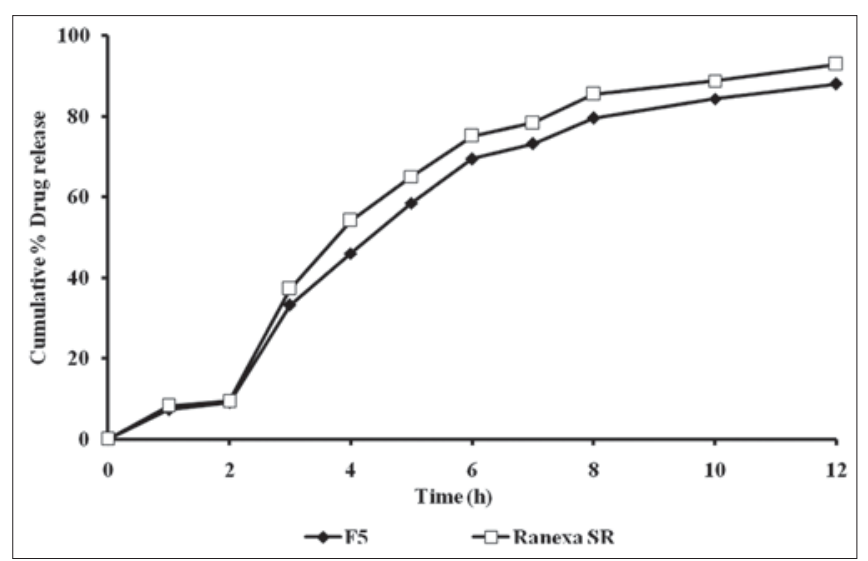

Figure 7: In vitro drug release profile of prepared RNZ microparticles' formulations. F5 (- -), F4 (-口-)

or decrease in the amount of EC. From the results it was observed that EU had exhibited a considerable effect on the drug release. In contrast, the results of the drug release revealed that release in $8 \mathrm{~h}$ varies in linear fashion with increased amount of EU and decreased amount of EC. Time taken for $50 \%$ drug release $(\mathrm{t} 50 \%)$ varies in a nonlinear fashion.

The data of the in vitro release studies was fitted into various mathematical models to determine the best-fit model. The results indicated that the best-fit models were the Peppas and Higuchi models. In all the cases the value of intercept, A was found to be less than 0.5. This indicates that the release of the drug from all the formulations followed the Fickian mechanism. The amount of drug released versus the square root of time was plotted. The plot should be linear if the release of the drug from the delivery system is diffusion-controlled. The dissolution graphs were found to be linear and the results inferred that the drug release from the microparticle formulation was by diffusion.

\section{CONCLUSION}

The objective of this study was to prepare and evaluate microparticles of an EU and EC mixture loaded with RNZ for controlled release by the phase separation method. Spherical discrete microparticles were obtained. The prepared microparticles exhibited good micromeritic properties. From the results of the particle size analysis it was clear that all the process variables were within the limits and the process is reproducible. FT-IR studies indicated that there was no interaction between the drug and the polymers in the prepared microparticles. The DSC thermograms obtained from the pure drug and the formulation showed no significant shift in the endothermic peaks confirming the stability of the drug in the formulation. The in vitro drug release studies showed 
Table 8: Formulations, response, and predicted values of RNZ microparticles

\begin{tabular}{|c|c|c|c|}
\hline Formulation & Response variable & Observed value & Predicted value \\
\hline \multirow{3}{*}{ F1 } & $1 \mathrm{~h}(\%)$ & 6.51 & 6.48 \\
\hline & $12 \mathrm{~h}(\%)$ & 81.2 & 81.32 \\
\hline & $\mathrm{t}_{50} \mathrm{~h}$ & 4.30 & 4.32 \\
\hline \multirow[t]{3}{*}{$\mathrm{F} 2$} & $1 \mathrm{~h}(\%)$ & 5.81 & 5.91 \\
\hline & $12 \mathrm{~h}(\%)$ & 77.24 & 77.41 \\
\hline & $\mathrm{t}_{50} \mathrm{~h}$ & 4.20 & 4.16 \\
\hline \multirow[t]{3}{*}{ F3 } & $1 \mathrm{~h}(\%)$ & 7.15 & 7.24 \\
\hline & $12 \mathrm{~h}(\%)$ & 82.91 & 83.01 \\
\hline & $\mathrm{t}_{50} \mathrm{~h}$ & 3.50 & 3.42 \\
\hline \multirow[t]{3}{*}{$\mathrm{F} 4$} & $1 \mathrm{~h}(\%)$ & 7.67 & 7.81 \\
\hline & $12 \mathrm{~h}(\%)$ & 71.33 & 71.42 \\
\hline & $\mathrm{t}_{50} \mathrm{~h}$ & 4 & 4.01 \\
\hline \multirow[t]{3}{*}{ F5 } & $1 \mathrm{~h}(\%)$ & 7.35 & 7.35 \\
\hline & $12 \mathrm{~h}(\%)$ & 87.98 & 87.98 \\
\hline & $\mathrm{t}_{50} \mathrm{~h}$ & 3.40 & 3.4 \\
\hline \multirow[t]{3}{*}{ F6 } & $1 \mathrm{~h}(\%)$ & 6.81 & 6.87 \\
\hline & $12 \mathrm{~h}(\%)$ & 80.5 & 80.63 \\
\hline & $\mathrm{t}_{50} \mathrm{~h}$ & 4.10 & 4.09 \\
\hline \multirow[t]{3}{*}{ F7 } & $1 \mathrm{~h}(\%)$ & 5.56 & 5.41 \\
\hline & $12 \mathrm{~h}(\%)$ & 75.1 & 75.69 \\
\hline & $\mathrm{t}_{50} \mathrm{~h}$ & 4.05 & 4.52 \\
\hline \multirow[t]{3}{*}{ F8 } & $1 \mathrm{~h}(\%)$ & 7.41 & 7.36 \\
\hline & $12 \mathrm{~h}(\%)$ & 81.26 & 81.34 \\
\hline & $\mathrm{t}_{50} \mathrm{~h}$ & 3.50 & 3.49 \\
\hline \multirow[t]{3}{*}{ F9 } & $1 \mathrm{~h}(\%)$ & 6.21 & 6.34 \\
\hline & $12 \mathrm{~h}(\%)$ & 71.5 & 71.42 \\
\hline & $\mathrm{t}_{50} \mathrm{~h}$ & 4.05 & 4.01 \\
\hline \multirow[t]{3}{*}{ F10 } & $1 \mathrm{~h}(\%)$ & 6.21 & 6.32 \\
\hline & $12 \mathrm{~h}(\%)$ & 83.66 & 83.74 \\
\hline & $\mathrm{t}_{50} \mathrm{~h}$ & 3.40 & 3.46 \\
\hline
\end{tabular}

that the release of the drug was found to be diffusioncontrolled. Results of dissolution studies for formulation F5 and the marketed product showed that both have nearly similar release profiles. From the results, it can be concluded that the microparticles' formulation is easy to administer, simple, and economical with increased patient compliance. Hence RNZ could be formulated into microparticles as a controlled drug release dosage form by the phase separation method.

These results demonstrate the potential use of EU and EC combinations for fabrication of delivery systems of other water soluble drugs in a controlled manner.

\section{REFERENCES}

1. Vyas SP, Khar KR. Controlled drug delivery concepts and advances. $1^{\text {st }}$ ed. 2002. p. 1-51.

2. Brahmankar DM, Jaiswal BS. Biopharmaceutics and pharmacokinetics a treatise. $1^{\text {st }}$ ed. 1995. p. 19-43.

3. Stanley WC. Ranolazine: New approach for the treatment of stable angina pectoris. Expert Rev Cardiovasc Ther 2005;3:821-9.

4. Huang J, Wigent RJ, Bentzley CM, Schwartz JB. Nifedipine solid dispersion in microparticles of ammonio methacrylate co-polymer and ethyl cellulose binary blend for controlled drug delivery. Int J Pharm 2006;319:44-54.

5. Ohwavworhu F, Adelakun T. Phosphoric acid-mediated depolymerization and decrystallization of $\alpha$-cellulose obtained from corn cob: Preparation of low crystallinity cellulose and some physicochemical properties. Trop J Pharm Res 2004;4:509-16.

6. Cui F, Cun D, Tao A, Yang M, Shi K, Zhao M, et al. Preparation and characterization of melittin-loaded poly (DL-lactic acid) or poly (DL-lacticco-glycolic acid) microspheres made by the double emulsion method. J Control Release 2005;107:310-9.

7. Sultana Y, Shalini M, Maurya DP, Kumar D, Das M. Preparation and in vitro characterization of diltiazem hydrochloride loaded aliginate microspheres. Pharm Dev Technol 2009;14:321-31.

8. Hekmatara T, Regdon G, Sipos P, Erős I, Pintye-Hódi K. Thermoanalytical study of microspheres containing diltiazem hydrochloride. J Therm Anal Calorim 2006;86:287-90.

9. Yan X, Gemeinhart RA. Cisplatin delivery from poly (acrylic acid-co-methyl methacrylate) Microparticles. J Control Release 2005;106:198-208.

10. Kumara A, Lahiri SS, Singh H. Development of PEGDMA: MAA based hydrogel microparticles for oral insulin delivery. Int J Pharm 2006;323:117-24.

11. United States of Pharmacopoeia. 22 ${ }^{\text {nd }}$ Revision, The United State Pharmacopoeial Convention, Rockville. 1989.

12. Liu L, Che B. Preparation of monolithic osmotic pump system by coating the indented core tablet. Eur J Pharm Biopharm 2006;64:180-4.

How to cite this article: Gowda DV, Gowrav MP, Gangadharappa HV, Khan MS. Preparation and evaluation of mixture of eudragit and ethylcellulose microparticles loaded with ranolazine for controlled release. J Young Pharmacists 2011;3:189-96.

Source of Support: Nil, Conflict of Interest: None declared.

\section{ED Query}

Q1: Can you provide the value of $X$ \& $Y$ axis??? Its not readable hence not retype. Author is not given the high resolution figure.

\section{Announcement}

\section{Android App}

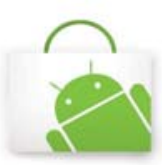

A free application to browse and search the journal's content is now available for Android based mobiles and devices. The application provides "Table of Contents" of the latest issues, which are stored on the device for future offline browsing. Internet connection is required to access the back issues and search facility. The application is compatible with all the versions of Android. The application can be downloaded from https://market.android.com/details?id=comm.app.medknow. For suggestions and comments do write back to us. 